\title{
New Solution for Urban Traffic: Small-type Monorail System
}

Takeo Kuwabara

Motomi Hiraishi

Kenjiro Goda

Seiichi Okamoto

Akira Ito

Yoichi Sugita
OVERVIEW: In Japan, the first urban straddle type monorail system, Tokyo Monorail, was put into operation in 1964. Since then, three more monorail systems have been constructed with the active participation of Hitachi in Kitakyushu, Osaka, and Tama. A monorail system is now being constructed in Okinawa; it is scheduled to start operation in 2003. The straddle type monorail can be constructed using the space above public roads without disturbing everyday traffic. Monorail trains with rubber tires are environmentally friendly and produce little noise and vibration. The straddle type monorail has become an important part of the urban public transportation system, chiefly because of its many advantages over other transportation means including the subway. These advantages include (1) improved environment, (2) a shorter construction period, and (3) lower costs. Thus, the monorail system in Japan is an effective solution to environmental problems and traffic congestion in urban cities, which also stimulates local economy. The demand for urban monorail systems has recently begun to come from smaller local cities where the daily ridership is much lower than that in Tokyo, Osaka, Kitakyushu, and other major cities in Japan. To enhance the financial viability of monorail construction in smaller cities and to construct smaller monorails, the Japan Monorail Association (JMA) set up a research committee to investigate the development of a small monorail. This committee, mainly headed by Hitachi, carried out comprehensive research of the market demand for monorail systems and initiated the development of a compact monorail. Hitachi developed a number of new design elements including an articulated bogie to enable trains to negotiate sharp curves. We also worked to design a compact and light monorail that makes use of next-generation signal systems. These basic elements can also be used for other people-mover systems in amusement parks, airports, and business complexes.

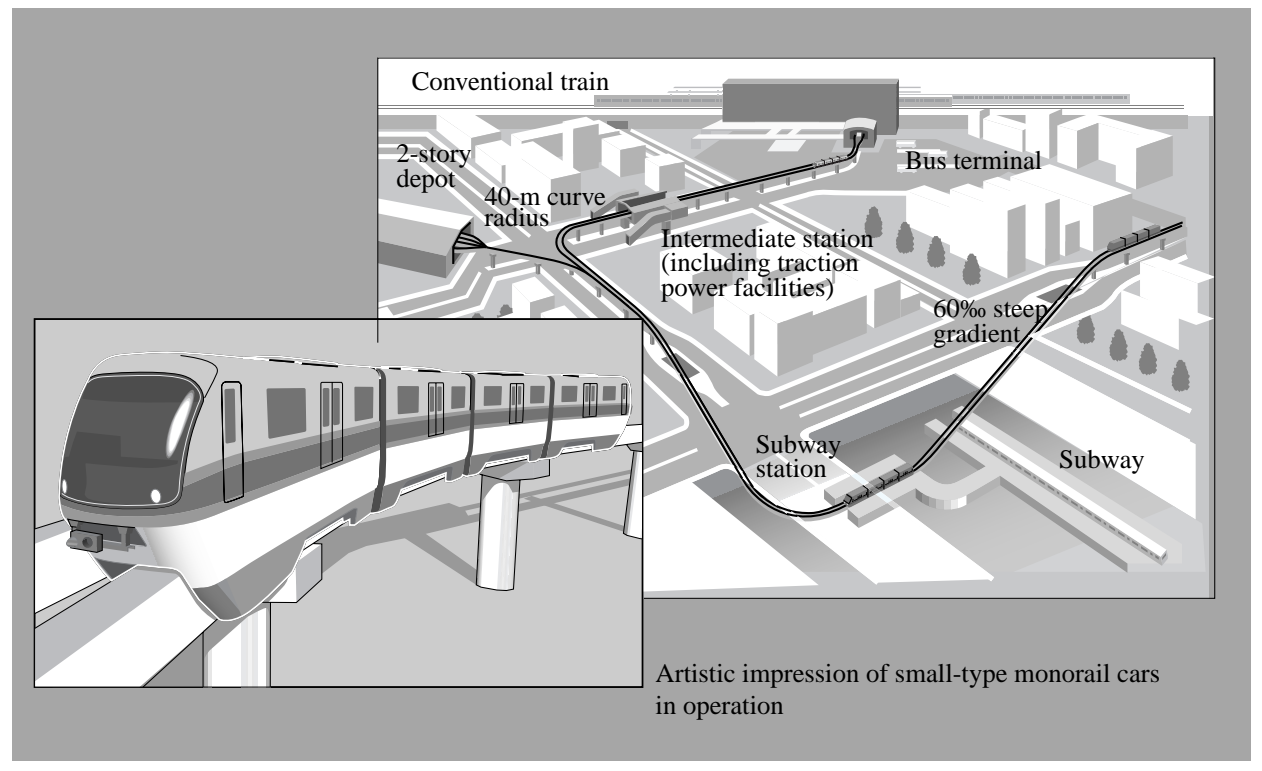

Fig. 1-Concept of New, Smalltype Monorail System in Harmony with the Urban Amenity.

Based on monorail know-how obtained from past construction projects, we developed a straddle type small monorail system with compact, standard, and low-cost configuration that meets the transportation needs of mediumand small-size cities. This smalltype monorail system has a number of features that make it flexible toward the requirements of various transportation agencies. 


\section{INTRODUCTION}

HITACHI has already completed the development of a small-type monorail system that meets the needs for economical construction and smaller monorails in regional cities. This paper describes the main features of our small-type monorail system.

\section{TECHNICAL FEATURES}

A reduced axle load is one of the main features of the guideway structure of our monorail train. In our train, the load on axles is 8 tons per axle instead of 10 to 11 tons per axle as in large conventional monorail trains. The main features of the small-type monorail system are these:

(1) Small and light vehicles.

- We have improved our vehicle design technologies to produce an economical vehicle.

- The train models have been standardized (two models are currently available).

- The exterior of the trains can be decorated with colored films.

- Seats in the trains can be arranged based on customers' specifications.

(2) Greater passenger carrying capacity (see Fig. 2).

- The passenger carrying capacity of a 4-car vehicle is 200 passengers (based on $0.3-\mathrm{m}^{2} /$ passenger standard occupancy) and passenger loading capacity in terms of pphpd (passenger per hour per direction) is 3,000 pphpd (for an operating headway of $4 \mathrm{~min}$ ).

- The daily passenger volume is 25,000 to 30,000 passengers.

(3) The cost of our system is $50 \%$ that of large-type monorail system.

- The total construction cost has been reduced to half that of large-type monorail system.
(4) Right-of-way for small-type monorail systems

- The guideway structure and station building can be constructed above narrow streets.

- Routes can be flexibly designed along existing roads and streets with a $40-\mathrm{m}$ curve radius and a $6 \%$ gradient.

(5) Smooth and seamless connection to other means of transportation

- We improved platform design to make transfers easier.

- The monorail can be built underground.

\section{COST CONSIDERATIONS}

(1) Optimization of technical specifications

- Our system features small and light vehicles, reduced train length, reduced number of passenger doors, which in turn reduces the guideway structure, station platform length, and the number of platform screen doors.

- Due to the use of traction power substations operating at $2,000 \mathrm{~kW}$, we can use commercial incoming power lines at substations, which reduces the amount of space for substations.

- The signaling system is equipped with an electronic interlocking device, which eliminates unnecessary cables and wiring. New regenerative power absorbing facilities have been installed to replace the regenerative power facilities on the wayside of the tracks.

- To reduce the amount of required space for depots and train storage yards, train lines can be constructed on the 2nd floor and the operation control and maintenance center will be located on the ground floor.

(2) Compact station buildings

- Side-platform arrangement for intermediate

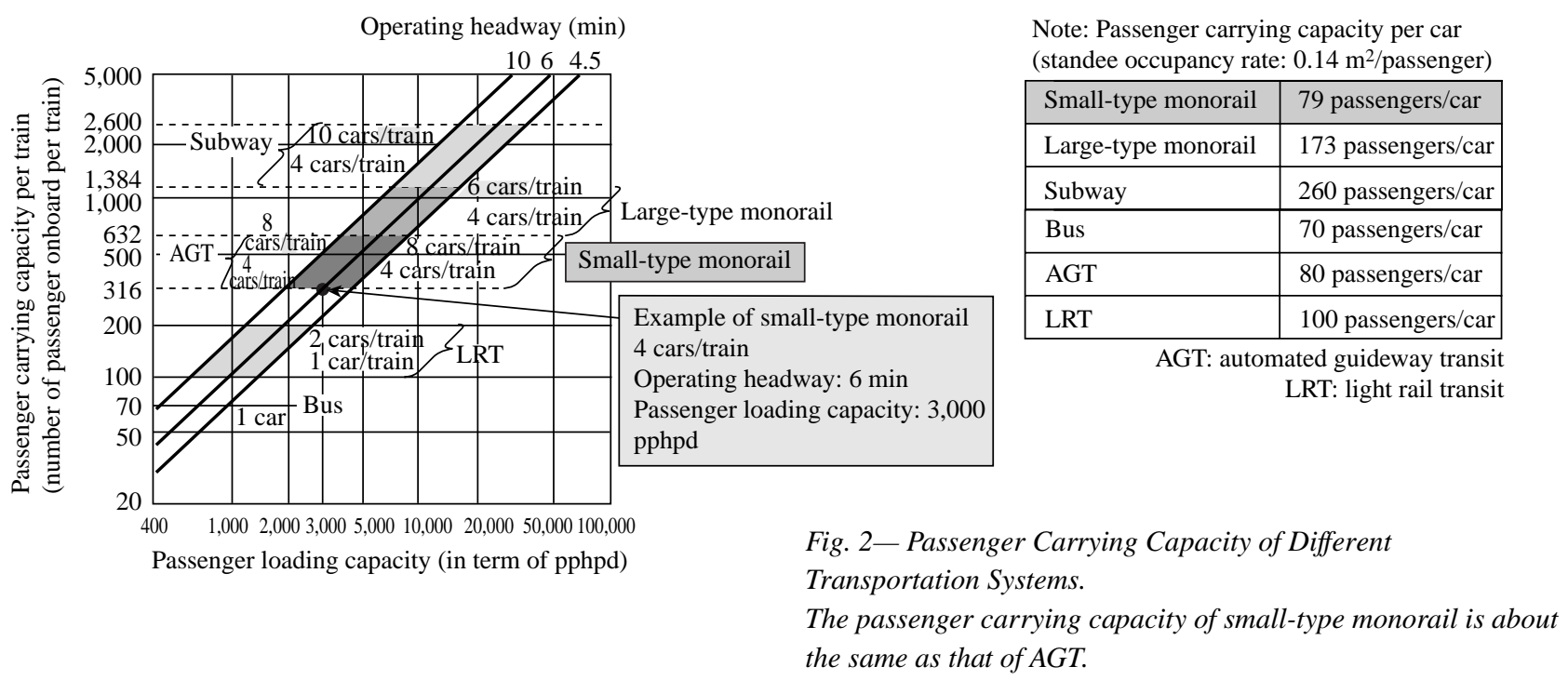


stations eliminates the need for concourse floors and makes station buildings 2-story structures rather than 3-story structures.

- There are no escalators at intermediate stations, only elevators and stairs.

(3) Standardized design

- Train components have been standardized, except for passenger seating arrangement and vehicle exterior for which there are two standard models.

- Making the intermediate station a side-platform type, instead of an island-platform type, keeps the tracks straight and simplifies station structure.

(4) Other features

- Using commercial incoming lines to power station equipment eliminates the need for low-voltage distribution networks and additional cables.

- The prestressed concrete (PC) tracks and steel track girders were made rectangular to reduce the cost of constructing the guideway structure.

- The signal, operation control, and communication systems were integrated into one system to reduce costs.

- The trolley wire design of power feeder lines has been simplified.

\section{SYSTEM CONFIGURATION}

\section{Comparing Our System with Conventional} Large-type Monorails

Fig. 3 compares our small-type monorail with a conventional large-type monorail.

\section{Monorail Trains}

The goals in designing the small-type monorail were (1) to reduce the number of cars in a train and (2) to make train cars lighter and more compact. This reduction in size has a remarkable cost-saving effect since the loading impact on the guideway structure becomes smaller.

(1) Because there is not much space under the frame of a monorail car to install equipment, we used an articulated bogie for our train.

(2) To enable the train to negotiate sharp curves to follow narrow roads in local cities, the minimum curve radius was set at $40 \mathrm{~m}$.

After we completed the design of the new bogie, we carried out a series of tests on a prototype bogie by

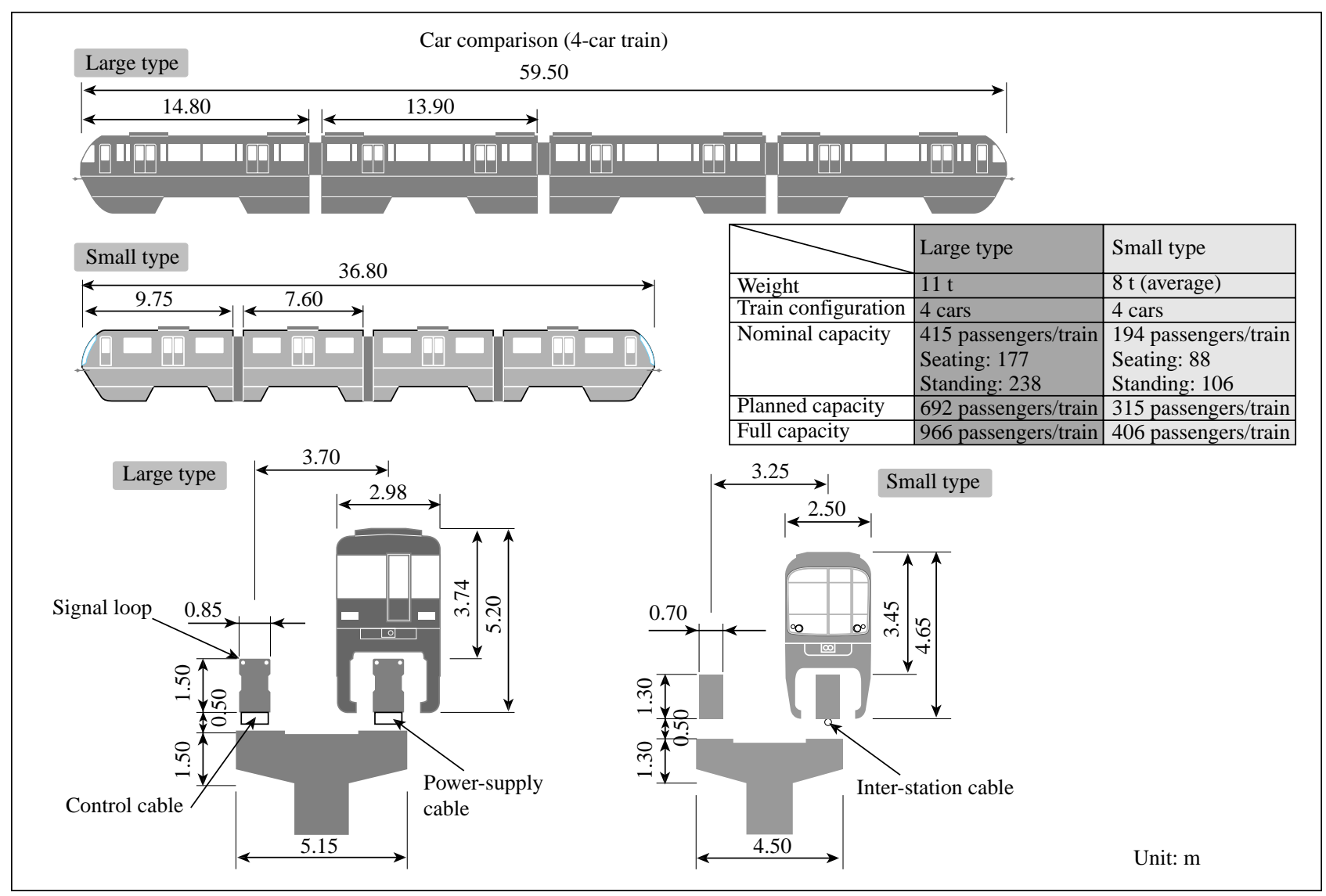

Fig. 3- Large-type and Small-type Monorails.

Small-type monorail system reduces the cross section of guideway structure and stations, and simplifies cable laying between stations. 


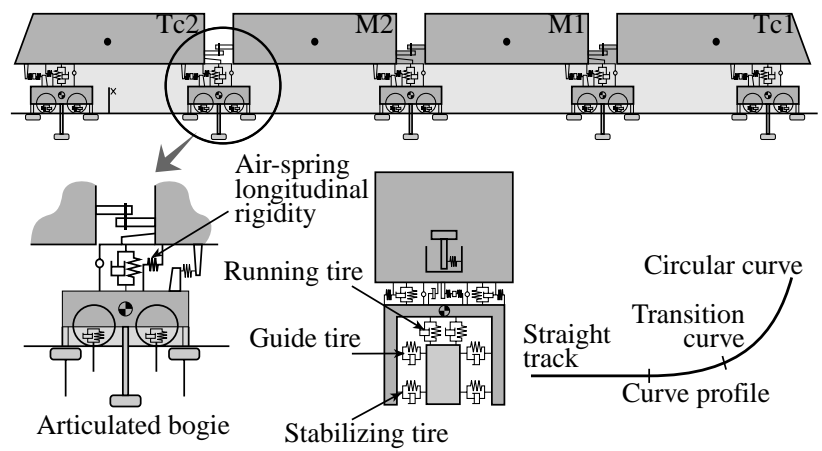

Fig. 4-Dynamic Simulation Model.

A design verification model was developed to examine the articulated-bogie system of the small-type monorail, and the riding comfort of passengers was evaluated when the train was passing a small curve with a 40-m radius.

simulating actual operating conditions.

(1) To reduce the increased load on the axles due to a smaller number of axles supporting the overall weight of the train, the average axle load is controlled at 8 tons per axle.

(2) To increase passenger comfort, the wheel springs and damper systems of the bogies have been carefully re-designed based on dynamic simulation results (see Fig. 4).

(3) A finite element method (FEM) was used to design a light bogie frame that is $15 \%$ lighter than that of a conventional bogie.

Experiments were performed to ensure that the tire slip angle takes into account the guiding tire force that can become excessive when the train passes a small curve. The results showed (see Fig. 5) that due to reduced air-spring longitudinal rigidity, the lifetime of the tires was the same as that in conventional systems while our small-type train could also negotiate sharp curves.

\section{Power Supply, Signal, Operation Control, and Communication Systems}

(1) To make the train compatible with other small transportation means, we used DC $750 \mathrm{~V}$ as an incoming line voltage. Although AC $600 \mathrm{~V}$ would be effective in terms of reducing the weight of train, it would not be cost-effective on the whole due to an increase in number of traction power facilities on the wayside of the tracks.

(2) Instead of the conventional low-voltage distribution network system in which relevant cabling work is provided by the system supplier, we used a commercial network from a utility company to power facilities allocated to each station.

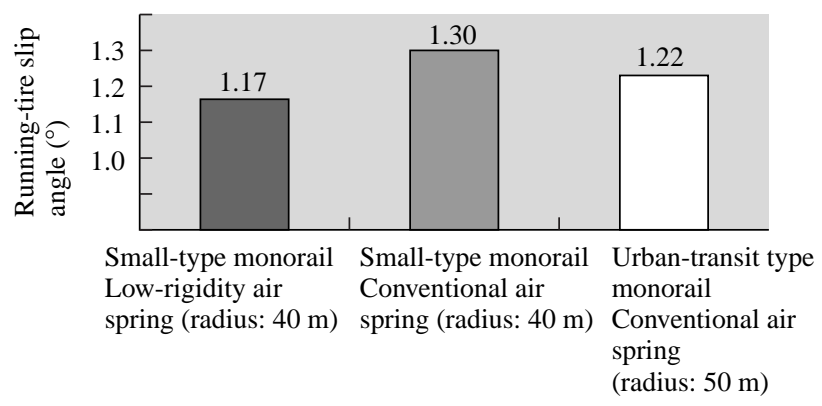

(a) Decrease in running-tire slip angle

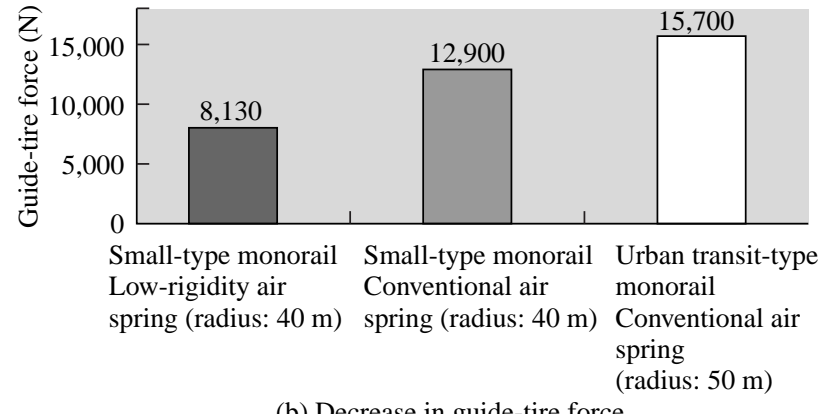

Fig. 5-Results of Dynamic Simulation.

Design elements affecting the lifetime of various tires in relation to the train's ability to pass small curves were analyzed, and an air-spring constant that can ensure the riding comfort equivalent to that of conventional systems was determined.

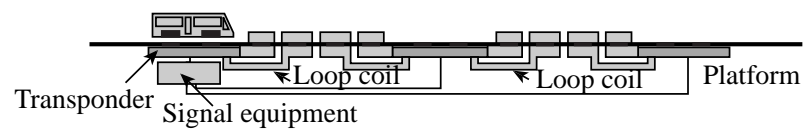

(a) Conventional system

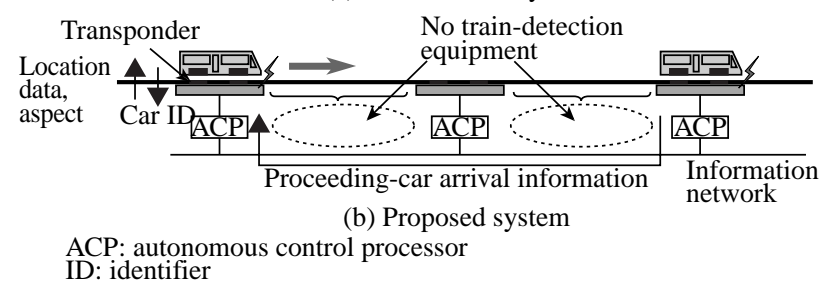

Fig. 6- Signal and Communication Systems.

The proposed system does not require the continuous loop and relevant cabling.

(3) The conventional method of installing trolley wires was replaced by the use of a saw tooth blade pattern to simplify installation to enable the power collecting shoe to be worn out evenly and to prevent tear.

(4) The conventional system employs fixed block signaling system in which multiple train-detection equipment are installed between any two stations allowing only one train to exist in one loop-coil interval. Our small-type monorail system has a simple train detection system based on the optimal allocation of transponder devices according to the train running performance, which enables cable-less work among stations (see Fig. 6). 


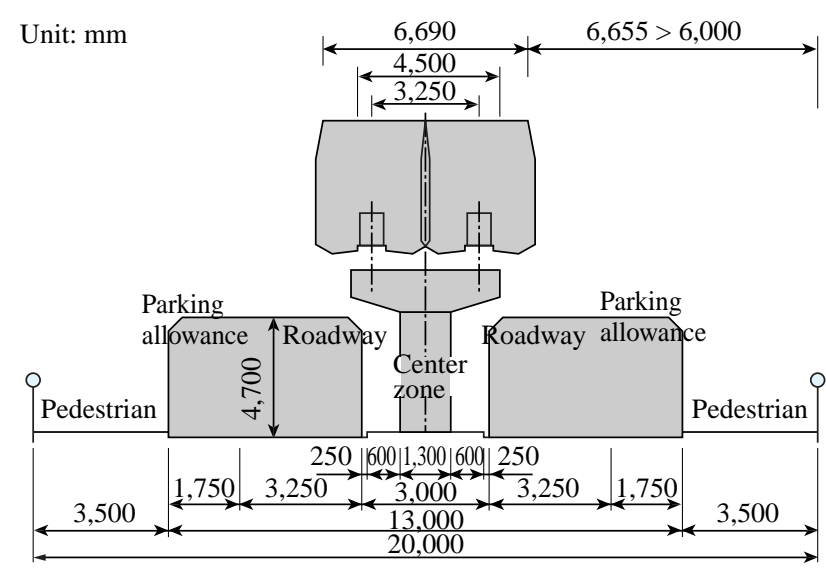

Fig. 7-Cross Section Layout of Guideway Structure in Smalltype Monorail System.

Small-type monorail system can be used on 20-m-wide roads.

(5) The signal, operation control (including traffic control, power control, passenger information/fault/ facilities management) and communication systems have been integrated into a single system by using ITrelated technologies including the Internet protocol (IP) and data transmission by optical fiber. This results in reduced capital, maintenance, and operating costs. (6) Right-of-way requirements for construction: Based on the results of these achievements described above, we are able to demonstrate the reduction in size and weight satisfying the structural requirements to construct above narrow streets and space (see Fig. 7).

\section{CONCLUSIONS}

This paper describes the development and features of small, straddle type monorail system. We at Hitachi are committed to developing straddle type monorails to meet our customers' requirements and objectives.

\section{REFERENCES}

(1) Japan Monorail Association (JMA), "Research on Urban Monorails Corresponding to Actual Demand," May 2000 in Japanese.

(2) M. Sugawara, "Research on Urban Monorails Corresponding to Actual Demand," Journal of Japan Monorail Association (JMA), No. 91, 2-26, June 2000 in Japanese.

(3) K. Iwasaki et al., "Research on Trucks for Small Straddle-type Monorails," Journal of Japan Monorail Association (JMA), No. 99, 44-47, April 2000 in Japanese.

\section{ABOUT THE AUTHORS}

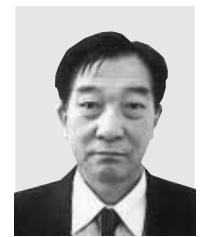

Takeo Kuwabara

Joined Hitachi, Ltd. in 1960, and now works at the Monorail Systems Integration Department of the Transportation Systems Division, Power \& Industrial Systems. He is currently engaged in the development of small-type monorail systems. Mr. Kuwabara can be reached by e-mail at takeo_kuwabara@pis.hitachi.co.jp.

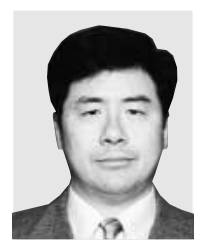

\section{Motomi Hiraishi}

Joined Hitachi, Ltd. in 1974, and now works at the Transportation Systems Division of the Kasado Administrative Division, Power \& Industrial Systems. He is currently engaged in the design of monorail cars. Mr. Hiraishi is a member of the Japan Society of Mechanical Engineers, and can be reached by e-mail at hiraishi@kasado.hitachi.co.jp.

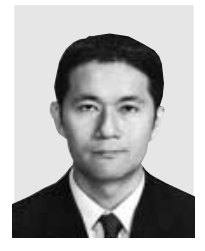

\section{Kenjiro Goda}

Joined Hitachi, Ltd. in 1995, and now works at the 5 th Department of the Mechanical Engineering Research Laboratory of the Research \& Development Group. He is currently engaged in the simulation of rolling stock. Mr. Goda can be reached by e-mail at goda@gm.merl.hitachi.co.jp.

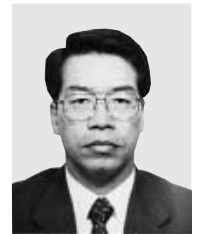

\section{Seiichi Okamoto}

Joined Hitachi, Ltd. in 1978, and now works at the Monorail Systems Integration Department of the Transportation Systems Division, Power \& Industrial Systems. He is currently engaged in the development of monorail systems. Mr. Okamoto can be reached by e-mail at seiichi_okamoto@pis.hitachi.co.jp.

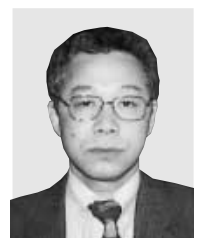

Akira Ito

Joined Hitachi, Ltd. in 1971, and now works at the Substation Engineering Division of the Power \& Industrial Systems Division, Power \& Industrial Systems. He is currently engaged in the design of substation systems. Mr. Ito can be reached by e-mail ata_Itou@cm.kokubu.hitachi.co.jp.

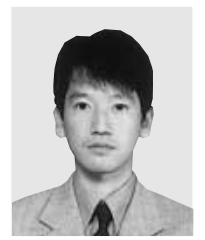

\section{Yoichi Sugita}

Joined Hitachi, Ltd. in 1992, and now works at the Information Control 2nd Department of Hitachi Research Laboratory of the Research \& Development Group. He is currently engaged in the development of signal-and-safety systems for small-type monorails. Mr. Sugita is a member of the Institute of Electrical Engineers of Japan and the Society of Instrument and Control Engineers, and can be reached by e-mail at ysugita@hrl.hitachi.co.jp. 